\title{
MATEMÁTICA FINANCEIRA: FORMAÇÃO E CIDADANIA
}

Sandra Formagini ${ }^{1}$

\section{RESUMO}

O presente estudo tratará a questão das metodologias utilizadas no ensino da Matemática Financeira, uma abordagem quanto a sua utilização na formação do educando, quanto a aspectos morais e sociais. Destaca a importância da resolução de problemas como metodologia diferenciada para o ensino da disciplina, trata a matemática como pressuposto para uma atividade contextualizada, auxiliando no processo ensino aprendizagem. Abrange a educação matemática como um todo, fazendo uma breve abordagem sobre a história da Matemática Financeira. Em síntese, destaca a importância e a aplicabilidade da disciplina como ciência, destacando sua função como meio de produzir conhecimentos científicos e sua função formadora no que tange aspectos sociais, auxiliando na formação de seres críticos, pensantes e atuantes na sociedade.

Palavras-Chave: Matemática financeira, metodologia, ciência, cidadania.

\section{ABSTRACT}

This present study will treat the question of methodology in the teaching of Financial Mathematics, an approach for application in formation the student, so moral and social aspects. It detaches the importance of solving problems as varied methodology for teaching the discipline, it treat the mathematics as a presupposed for contextualized activity, assisting in teaching learning process. It covers the mathematics education as a whole, making a short approach on the history of Financial Mathematics. In summary detaches the importance and applicability of the discipline as a science, detaching its function as a means of producing scientific knowledge and its forming function in social aspects, assisting in the formation of critical beings, thinking and acting in society.

Keywords: Financial Mathematics, methodology, science, citizenship.

\footnotetext{
${ }_{1}^{1}$ Docente na Universidade Alto Vale do Rio do Peixe (UNIARP). sandraformagini@yahoo.com.br
} 


\section{INTRODUÇÃO}

O presente estudo refere-se à Matemática Financeira, formação e cidadania, seu principal objetivo é desenvolver e refletir a importância do ensino da Matemática Financeira como recurso para a formação e construção da cidadania; visa também analisar o sentido da utilização da resolução de problemas no processo ensino aprendizagem, desenvolvendo estudos que possibilitem a utilização de novas metodologias no ensino de Matemática Financeira, relacionando conhecimentos ao assunto abordado na resolução de situações-problemas, associando conhecimento cientifico com situações do cotidiano. Apresenta novas concepções sobre o ensinar matemático voltado para a realidade do educando.

Ressaltando que a matemática está presente em nossas vidas, desde uma simples contagem até o uso em complexos computadores. Pode parecer a princípio que ela não tem utilização e é desconectada do mundo real, o que não é verdadeiro; é de suma importância na vida das pessoas, até mesmo nas situações mais simples do cotidiano.

Contudo, para mudar o atual contexto faz-se necessário uma nova abordagem sobre o assunto e também nova metodologia e estratégias aplicadas no processo ensino aprendizagem, não diferentes a isso, está o ensino da Matemática Financeira, sendo esta ferramenta muito útil no processo de formação do aluno, cidadão consciente e participativo que as escolas procuram preparar.

Pois esta é uma ciência que tem por objetivo desenvolver o raciocínio lógico e que serve de base para tantas outras ciências desde os primórdios, é de total importância na sociedade atual; sociedade esta, cada vez mais exigente e competitiva, que exige o máximo de cada cidadão, onde se sobressaem as mentes mais criativas e ousadas, isso demonstra a necessidade da matemática no ensino fundamental e médio, pois está presente nos mais variados ramos da atividade humana.

Ressaltando que o ensino da matemática não deve se basear apenas na prática de exercícios e sim, partir da curiosidade dos alunos, adaptando-a ao meio social em que o educando está inserido, não deixando de lado temas importantes e científicos, considerando sempre, que o aluno é agente ativo na construção de seu conhecimento. 
Estudos já demonstram que a origem da matemática vem da necessidade humana em resolver problemas práticos e que foi evoluindo e se aperfeiçoando de acordo com as argumentações e curiosidades da humanidade; a Matemática Financeira não é diferente, pois fornece o instrumental necessário à avaliação de negócios de modo a identificar os recursos mais atraentes em termos de custos e os mais rentáveis no caso de investimentos financeiros ou de bens de capital. A Matemática Financeira tem extrema importância para a tomada de decisões na empresa e sua aplicação quando bem desenvolvida, traz maior rentabilidade possibilitando o processo de maximização nos resultados. Nas situações mais simples e corriqueiras do dia-a-dia, como por exemplo, se você tem dinheiro em algum tipo de poupança/investimento, ou em um pequeno negócio, ou ambos e quer comprar um carro ou um eletrodoméstico; você deve decidir se paga à vista, mediante saque de aplicação ou de capital de giro da empresa, ou se acolhe o financiamento oferecido pelo vendedor, às ferramentas da Matemática Financeira vão indicar - the a melhor decisão.

Por fim, são apresentados alguns argumentos que demonstram a participação do ensino da Matemática Financeira e a disciplina como um todo na formação de pessoas críticas, pensantes e reflexivas.

\section{O QUADRO ATUAL DO ENSINO DA MATEMÁTICA NO BRASIL}

Entre os desafios enfrentados pelo Brasil em relação ao ensino da matemática, destaca-se a falta de formação profissional qualificada, restrições às condições de trabalho, faltam políticas educacionais efetivas e as interpretações adequadas às concepções pedagógicas. Mas muitos esforços vêm sendo empreendidos para minimizar esses problemas, como por exemplo, as Universidades, Secretarias de Educação e outras instituições têm produzido materiais de apoio à prática do professor. O que se observa em termos escolares é o fato de os conteúdos matemáticos serem tratados isoladamente e são apresentados e explicados num único momento e quando são retomados, são utilizados apenas como ferramentas para a aprendizagem de novas noções, não se considera para que o aluno consolide e amplie um novo conceito com base no já apreendido. É necessário que ele associe as novas representações ou conexões com outros conceitos. 
Outra distorção refere-se à má interpretação da idéia de contexto, ao se trabalhar apenas com o que se supõe fazer parte do dia a dia do aluno, que embora seja importante, deve-se considerar que esses significados podem ser explorados em outros contextos, caso contrário, muitos conteúdos podem ser ignorados por serem julgados sem uma análise adequada. Algumas sugestões são elaboradas em quase todas as propostas curriculares como por exemplo basear-se na história da matemática como assunto específico; a utilização de material lúdico, jogos e brincadeiras, mas é claro que fazendo uso adequado desses recursos para que não se projetem expectativas e análises indevidas.

Os obstáculos apontados revelam o desempenho insatisfatório dos alunos revelados pelas elevadas taxas de retenção à disciplina, são estes uns dos desafios a serem vencidos pelos profissionais da educação, reverter esta situação é mostrar aos educandos a importância de se conhecer esta ciência e sua aplicabilidade, pois os problemas enfrentados são antigos e atuais e esta é uma tarefa que requer operacionalização efetiva de novos métodos, com a inclusão de novos elementos.

\section{MATEMÁTICA NO ENSINO MÉDIO}

À medida que nos integramos a uma sociedade da informação crescente globalizada, é necessário que a educação se volte para o desenvolvimento das capacidades de comunicação, de resolver problemas, de tomar decisões, de aperfeiçoar conhecimentos, valores e de trabalhar em sociedade; quando se estabelecem parâmetros para a organização do ensino da Matemática no Ensino Médio, deseja-se adequar seu desenvolvimento e promoção de alunos com diferentes motivações, interesses e capacidades, possibilitando assim condições para a sua inserção num mundo em mudança e contribuindo para desenvolver as capacidades que deles serão exigidas em sua vida social e profissional. Em um mundo onde as necessidades sociais, culturais e profissionais ganham novos contornos, todas as áreas requerem alguma competência em Matemática e a possibilidade de compreender conceitos e procedimentos matemáticos é necessário, tanto para tirar conclusões e fazer argumentações, quanto para o cidadão agir como consumidor prudente ou tomar decisões em sua vida pessoal e profissional. 
A Matemática no Ensino Médio tem um valor formativo, pois ajuda a estruturar o pensamento e o raciocínio dedutivo, é uma ferramenta que serve para a vida cotidiana e para muitas tarefas especificas em quase todas as atividades humanas. Em seu papel formativo, a Matemática contribui para o desenvolvimento de processos de pensamentos e a aquisição de atitudes, cuja utilidade e alcance transcendem o âmbito da própria Matemática, podendo formar no aluno a capacidade de resolver problemas genuínos, gerando hábitos e investigação, proporcionando confiança e desprendimento para analisar e enfrentar situações novas, propiciando uma visão ampla e cientifica da realidade. Quanto ao seu caráter instrumental, a Matemática no Ensino Médio deve ser vista pelo aluno como um conjunto de técnicas e estratégias para serem aplicadas a outras áreas do conhecimento.

Cabe à Matemática apresentar ao aluno o conhecimento de novas informações e instrumentos necessários, para que seja possível a ele continuar aprendendo. Saber aprender, é a condição básica para prosseguir aperfeiçoando-se ao longo de sua vida, no desenvolvimento da autonomia e da capacidade de pesquisa, para que cada aluno possa confiar em seu próprio conhecimento.

\title{
O CONHECIMENTO MATEMÁTICO
}

\begin{abstract}
A matemática caracteriza-se como forma de compreender e atuar no mundo e o conhecimento gerado nessa área do saber como um fruto da construção humana na sua interação constante com o contexto natural, social e cultural. (PCN, 1998, p.24).
\end{abstract}

A matemática é uma ciência presente na sociedade, não apenas no cotidiano das pessoas, mas também nas mais diversas instituições sejam de ensino ou de pesquisa, onde há uma impressionante produção de novos conhecimentos, que tem sua origem lógica e que servem como instrumentos na resolução dos mais diversos problemas científicos e tecnológicos. No entanto, não deve esquecer-se do valor especulativo, estético não imediatamente pragmático, pois ambas as forças impulsionam o trabalho matemático, uma delas o permanente, devido a suas mais diversas aplicações às atividades humanas, desde as mais simples até as mais complexas. De outro lado a especulação pura, a constante busca por respostas geradas da própria prática. 
Ciência que é fruto da imaginação, da criação e das invenções humanas que evoluiu de forma linear e organizada, surgiu do estudo e do reestudo dos paradigmas, da ruptura dos mesmos e da formulação de novas teorias, da experimentação e comprovação, considerando-se as mais diversas civilizações, que com suas culturas diferentes criavam a arte da matemática de acordo com suas necessidades. Deste modo, pode-se conceber o saber matemático como algo flexível e maleável às inter-relações entre os seus vários conceitos e entre os seus vários modos de representação, também permeáveis aos problemas nos vários outros campos científicos. Um saber matemático desse tipo pode ser o motor de inovações e de superação dos obstáculos, desde os mais simples até aqueles que significam verdadeiras barreiras no seu desenvolvimento.

O uso diário da aritmética e a apresentação de informações através de gráficos são fatos comuns no nosso dia a dia, estes são os aspectos elementares da matemática; é amplamente usada, mas freqüentemente de um modo invisível e inesperado. A matemática dos códigos de correção de erros é aplicada a aparelhos de $C D$ e a computadores, as fotos estonteantes de longínquos planetas enviadas, não poderiam ter sua clareza e sua qualidade sem esta matemática.

O desenvolvimento dos computadores foi iniciado nos EUA pelos matemáticos e lógicos, que continuam a dar importantes contribuições à teoria da ciência da computação, as ciências físicas (química, física, oceanografia, astronomia) requerem matemática para o desenvolvimento de suas teorias, a estatística fornece teoria e método para a análise de muitos tipos de dados; a matemática faz contribuições especiais ao estudo destas idéias, a saber, os métodos de definições precisas, argumentos cuidadosos e rigorosos, representação de idéias por meio de vários métodos, incluindo símbolos e fórmulas, figuras e gráficos, métodos de cálculo e a obtenção de soluções precisas de problemas claramente enunciados, ou afirmações claras do limite do conhecimento. Estas características permitem a matemática fornecer um fundamento sólido a muitos aspectos da vida cotidiana e oferecer uma compreensão das complexidades inerentes a situações aparentemente muito simples.

Por estas razões, matemática e cálculo têm sido associados desde os primeiros tempos até a atualidade, a matemática ao se manter próxima das outras ciências e da sociedade moderna, dá uma extraordinária contribuição para a 
humanidade. É impossível dissociar a história da humanidade dos impactos da matemática em cada fase da civilização, ela sempre esteve de forma marcante, a partir de meados do século 20 nova transição de fase parece ter ocorrido, reservando um lugar peculiar para a matemática no desenvolvimento da humanidade, por exemplo, modelos matemáticos precisos proporcionaram o sequenciamento genético e o coquetel antiviral no tratamento da AIDS, modelagem matemática para previsões climáticas, análise de dados estatísticos em ciências sociais, são exemplos de fundamental importância nos dias de hoje, além da viabilização dos recursos computacionais.

Podemos considerar que hoje a tendência de todas as ciências é cada vez mais se matematizarem em função do desenvolvimento de modelos matemáticos que descrevem os fenômenos naturais de maneira adequada em um ritmo intenso do desenvolvimento tecnológico dos tempos atuais que produz o seguinte fenômeno; é cada vez menor o tempo decorrente entre o desenvolvimento de uma teoria matemática e sua utilização prática. Em resumo, podemos afirmar que dominar o uso da matemática hoje em dia, é uma condição necessária para o sucesso em uma quantidade enorme de profissões e as projeções para o futuro próximo, indicam que esta tendência tende a se intensificar. A matemática em certo sentido é uma arte, a análise e a engenhosidade na obtenção da solução de um problema matemático possuem um valor estético intrínseco, uma série de resultados se encaixa magicamente num resultado final que surpreende ou encanta.

\section{RESOLUÇÃO DE PROBLEMAS}

No ensino da matemática o problema se estabelece justamente porque só se levam em consideração as atividades cognitivas de formação de representações e os tratamentos necessários em cada representação. No entanto o que garante a apreensão do objeto matemático, a contextualização, não é a determinação de representações ou as várias representações possíveis de um mesmo objeto, mas sim a coordenação entre estes vários registros de representação (NEHRING, 1999 p. 147).

O homem age sobre seu meio com o objetivo de transformar, assim como o meio leva o homem à ação efetiva transformando-se a si próprio, nesta relação, o homem é confrontado a situações problemas para melhor compreender e explicar a natureza, o que demonstra que o homem não vive isolado dentro do processo de 
construção e de aquisição do conhecimento, ele vive dentro de uma cultura matemática quando da resolução de um problema, esta cultura é o resultado de uma trama entre conhecimentos adquiridos no convívio social e conhecimentos científicos. Ao desenvolver uma reflexão sobre as várias formas de construção do conhecimento matemático, observa-se que a escola, na grande parte dos casos não considera a multiplicidade, demonstrando que ela se organiza sob um conceito de matemática estruturada com base em modelos únicos, imutáveis ao longo da história.

Por isso se faz necessário rever junto a escola a concepção do que vem a constituir uma atividade matemática, essa revisão implica que a escola deve passar a conceber as diversas dimensões de uma atividade matemática; do estabelecimento das idéias, de suas varias formas de representação, da comunicação e do poder de argumentação, dentro do grupo social ao qual os educandos estão inseridos.

Somente nesse sentido, podemos pensar em conceber uma educação matemática mais próxima de uma visão holística do conhecimento (D’Ambrósio, 1999).

A atividade matemática tem, portanto, dois níveis de representações importantes, o primeiro refere-se aos registros dos conceitos e da estruturação do pensamento, e o segundo refere-se à aplicabilidade do que foi aprendido; o que vem a reforçar a aplicabilidade da resolução de problemas, como metodologia para tornar o conhecimento matemático como algo mais próximo da realidade dos alunos, pois este, valoriza as idéias e o conhecimento prévio do educando, criando assim dentro da sala de aula um fórum democrático, onde há permanente confronto e troca de saberes. Nesse espaço, pode encontrar múltiplas formas de resolver uma situação problema, pois na educação, é de grande importância que se socialize e se valide as diferentes formas de representação do pensamento, sejam elas manipulativas mentais ou escritas.

É relevante compreender que não convém o uso do simples termo mudança de domínios, em lugar de interação entre domínios, pois não se trata de aprender conhecimentos de um domínio e aplicá-los para outros. Friso ainda que os conhecimentos ou as noções são as ferramentas, isto é, prevê-se o uso de conceitos, propriedades, procedimentos de cada domínio (MACHADO, 1999) 
A utilização da resolução de situações problemas em sala de aula envolve a organização e interpretação de dados, a identificação ou a criação de conceitos matemáticos que traduzam aspectos do mundo real e a volta ao mundo real para a validação dos resultados. A abordagem defendida pelo autor é a concepção de uma matemática voltada para todos, que incluam estudantes que um dia possam vir a gostar, desejar, precisar da matemática, defende-se um ensino/ aprendizagem que tanto prepare adequadamente os alunos para estudos mais aprofundados, quanto sirva para estudantes que não prosseguem estudos avançados nesta área.

A matemática está totalmente presente na criação e na utilização dos recursos tecnológicos e este fato deve ser considerado na escola, pois os alunos poderão compreender como os conhecimentos nesta área podem colaborar na melhor e maior participação das situações sociais.

Os Parâmetros curriculares Nacionais prevêem que é importante propor ao aluno situações em que ele possa coletar e organizar dados e utilizar recursos visuais adequados, para sintetizá-los, comunicá-los e permitir a elaboração de conclusões. Dentre as atitudes a serem desenvolvidas, deve-se destacar a capacidade de investigação e a perseverança na busca de resultados, valorizando o uso de estratégias de verificação de controle de resultados.

Para tanto esta nova abordagem do ensinar matemática, utilizando a resolução de situações problemas, vem a contribuir nas atividades escolares porque visa um conhecimento voltado para a realidade dos alunos, não perdendo a essência cientifica que tem. Ao se trabalhar uma situação problema, faz-se que o aluno vivencie um novo modo de aprender matemática, a partir de situações do mundo real e que, para sua solução requer a busca e a construção de conhecimentos matemáticos. Essa busca e a construção ocorrem, portanto, a partir de necessidades geradas por uma situação real e não imposta dentro de um currículo, tornando-se assim agente ativo na construção do saber e conquistando autonomia para tomar decisões na vida em sociedade. 


\section{A MATEMÁTICA FINANCEIRA}

\section{CONTEXTUALIZAÇÃO HISTÓRICA DA MATEMÁTICA FINANCEIRA}

É bastante antigo o conceito de juros, tendo sido amplamente divulgado e utilizado ao longo da história, esse conceito surgiu naturalmente quando o homem percebeu existir uma estreita relação entre o tempo e o dinheiro; processos de acumulação de capital e a desvalorização da moeda levariam normalmente a idéia de juros, pois se realizavam basicamente devido ao valor temporal do dinheiro.

As tábuas mais antigas mostram um alto grau de habilidade computacional e deixam claro que sistema sexagesimal posicional já estava de longa data estabelecida, há muitos textos que tratam da distribuição de produtos agrícolas e de cálculos aritméticos baseados nessas transações; as tábuas mostram que os sumérios antigos estavam familiarizados com todos os tipos de contratos legais e usuais, como faturas, recibos, notas promissórias, crédito, juros simples e compostos, hipotecas, escrituras de vendas e endossos.

Há tábuas que são documentos de empresas comerciais e outras que lidam com sistemas de pesos e medidas, muitos processos aritméticos eram efetuados com a ajuda de várias tábuas, das cerca de 400 tábuas, metade eram tábuas matemáticas, estas envolvem tábuas de multiplicação, tábuas de inversos multiplicativos, tábuas de quadrados e cubos e mesmo tábuas de exponenciais; quanto a estas, provavelmente eram usadas, juntamente com a interpelação em problemas de juros compostos, as tábuas de inversos eram usadas para reduzir a divisão à multiplicação.

Os juros e os impostos existem desde a época dos primeiros registros de civilizações existentes na terra, um dos primeiros indícios apareceu já na Babilônia no ano 2000 aC, nas citações mais antigas, os juros eram pagos pelo uso de sementes ou de outras conveniências emprestadas; os juros eram pagos sob a forma de sementes ou de outros bens, muitas das práticas existentes originaram-se dos antigos costumes de empréstimos e devolução de sementes e de outros produtos agrícolas.

A História também revela que a idéia se tinha tornado tão bem estabelecida 
que já existia uma firma de banqueiros internacionais em 575 aC, com os escritórios centrais da Babilônia, sua renda era proveniente das altas taxas de juros cobradas pelo uso de seu dinheiro para o financiamento do comércio internacional; o juro não é apenas uma de nossas mais antigas aplicações da Matemática Financeira, mas também seus usos sofreram poucas mudanças através dos tempos.

Como em todas as instruções que tem existido por milhares de anos, algumas das práticas relativas a juros têm sido modificadas para satisfazerem às exigências atuais, mas alguns dos antigos costumes ainda persistem de tal modo que seu uso nos dias atuais ainda envolve alguns procedimentos incômodos, entretanto, devemos lembrar que todas as antigas práticas que ainda persistem foram inteiramente lógicas no tempo de sua origem, por exemplo, quando as sementes eram emprestadas para a semeadura de uma certa área, era lógico esperar o pagamento na próxima colheita no prazo de um ano, assim o cálculo de juros anual, era mais razoável tão quanto o estabelecimento de juros compostos para o financiamento das antigas viagens comerciais, que não poderiam ser concluídas em um ano, conforme a necessidade de cada época foi se criando novas formas de trabalhar com relação tempo-juros.

Há tábuas nas coleções de Berlim, de Yale e do Louvre que contém problemas sobre juros compostos e há algumas tábuas em Istambul que parecem ter sido originalmente tábuas de a' para n de 1 a 10 e para a =9,16,100 e 225. Com essas tábuas podem-se resolver equações exponenciais do tipo $a^{\prime}=b$. em uma tábua do Louvre, de cerca de 1700 a.C., há o seguinte problema: por quanto tempo devese aplicar um certa soma de dinheiro a juros compostos anuais de $20 \%$ para que ela dobre?

$\mathrm{Na}$ época em que os homens viviam em comunidades restritas, tirando da natureza todos os produtos de que tinham necessidade, sem dúvidas, devia existir pouca comunicação entre as diversas sociedades, mas com o desenvolvimento do artesanato e da cultura e em razão da desigual repartição dos diversos produtos naturais, a troca comercial mostrou-se necessária, o primeiro tipo de troca comercial foi o escambo, fórmula segundo a qual, se trocam diretamente gêneros e mercadorias correspondentes a matérias primas ou a objetos de grande necessidade. Com a intensificação das comunicações entre os diversos grupos e a importância cada vez maior das transações, a prática do escambo direto tornou-se 
bem rapidamente um estorvo, não se podiam mais trocar mercadorias segundo o capricho de tal ou qual individuo, ou em virtude de um uso consagrado ao preço de intermináveis discussões; houve, portanto, a necessidade de um sistema relativamente estável de avaliações e equivalência, fundado num principio dando a definição de algumas unidades ou padrões fixos. Devido às varias formas de se estimar mercadorias, cada região com uma maneira especifica, foi ocasionando sérias dificuldades de aplicação, à medida que o comércio se desenvolvia, os metais desempenharam um papel cada vez maior nas transações comerciais, vindo a tornar-se a moeda de troca preferida dos vendedores e compradores, as avaliações das diversas mercadorias passaram a ser feitas quantitativamente pelo peso, cada uma delas, referindo a uma espécie de peso padrão, relativo a um ou outro metal.

A partir de então, graças ao padrão do metal, as mercadorias passaram a não mais ser trocadas ao simples prazer dos contratantes, mas em função de seu justo preço. Aprendendo a contar abstratamente e agrupar todas as espécies de elementos seguindo o princípio de base, o homem aprendeu assim a estimar, avaliar e medir diversas grandezas. Aprende igualmente a atingir e conceber números cada vez maiores, antes mesmo de ser capaz de dominar a idéia do infinito, pode também elaborar, várias técnicas operatórias e erguer os primeiros rudimentos de urna aritmética inicialmente pratica, antes de tornar-se abstrata e conduzir a álgebra, onde hoje temos a Matemática Financeira amplamente desenvolvida.

\section{MATEMÁTICA FINANCEIRA E A CIDADANIA}

Vivemos em um mundo globalizado, são centenas de informações que nos chegam a todo o momento, é para este mundo que a educação matemática deve voltar seus olhares, para uma clientela que precisa a todo o momento tomar decisões financeiras, até mesmo nas situações mais simples do dia-a-dia, não se pode esquecer que o aluno é ser social que interage em uma sociedade que esta em constante transformação e que esta em contato direto com as informações, inicialmente via publicidade, quando ficam a mercê das informações veiculadas, via contato físico quando tem a oportunidade de explorar as informações presentes, principalmente no comércio. As informações, tanto as qualitativas quanto as quantitativas requerem do cidadão um nível de alfabetização nem sempre elementar, esta alfabetização, no sentido mais amplo, implica em uma alfabetização 
matemática, tecnológica, cultural e ideológica.

O papel da aprendizagem matemática é de vital importância nos processos de leitura, interpretação, reflexão lógica e tomada de decisões; desde a análise da quantidade do produto e de seus componentes, de sua durabilidade e validade, da relação custo/ benefício até a decisão de compra e forma de pagamento, são utilizados conceitos matemáticos, que são aprendidos no ensino fundamental e médio; ainda pode-se dizer que a tomada de decisões de compra/ consumo implica questões financeiras, o que nos leva a questões a cerca de financiamentos, para isso espera-se que a escola consiga despertar em seus alunos a consciência das estratégias da publicidade e dos meios de comunicação, pois assim estará no rumo certo da formação do cidadão, da educação e do diálogo entre as pessoas.

Quando o que se aprende na escola contribui para a formação de um ser social e democrático aí sim ocorre educação, como escreve (SKOVSMOSE, 2001):

A matemática tem um campo extenso de aplicações. A matemática é aplicada em economia (macroeconomia e microeconomia), planejamento industrial, em diferentes formas de gerenciamento e em propaganda tanto quanto em campos tradicionais de aplicação de tecnologia. É freqüentemente difícil tanto, na escola primaria quanto na secundaria, apresentar exemplos ilustrativos de aplicações reais. Aplicações reais da matemática ficam normalmente escondidas, embora sejam muito importantes (SKOVSMOSE, 2001).

O ensino da Matemática Financeira no terceiro ano do ensino médio, é considerada uma das etapas finais da escolaridade e tal conteúdo deve se organizar de forma a proporcionar ao aluno a aquisição de uma parcela importante no conhecimento humano, deve auxiliar no desenvolvimento da leitura, na interpretação da realidade, desenvolvendo assim capacidades necessárias para a atuação na sociedade e também na sua vida profissional.

Sendo assim, a matemática financeira vai além de seu caráter instrumental, colocando-se como ciência com linguagem própria e métodos específicos de investigação, considerando que o enfrentamento das situações que o educando terá pela frente na escola e no prosseguimento de seus estudos, no trabalho e no exercício da cidadania requer mais do que informações, exigindo a mobilização de conhecimento e habilidades.

Aprender Matemática de uma forma contextualizada, integrada e 
relacionada a outros conhecimentos traz em si o desenvolvimento de competências e habilidades que são essencialmente formadoras, à medida que instrumentalizam e estruturam o pensamento do aluno, capacitando-o para compreender e interpretar situações, se apropriar de linguagens especificas, argumentar, analisar e avaliar, tirar conclusões próprias, tomar decisões, generalizar e para muitas outras ações necessárias à sua formação. (PCN, p.111)

Que a matemática tem papel formativo, tanto cientificamente quanto socialmente, não se discute muito, o fato é que as metodologias utilizadas em sala de aula devem mudar, a escola e educadores não podem desconsiderar que o aluno faz parte de uma sociedade em constantes mudanças, principalmente no que se refere as tecnologias é necessário prepará-los para estas tecnologias, por isso a aproximação da sala de aula com a realidade, esta mudança é um processo de construção de novas metodologias. A matemática financeira só vem a contribuir neste percurso, pois, possibilita o sujeito a fazer uma leitura de mundo, seja pela sua curiosidade, seja pela experimentação que vivencia no grupo social, o educando traz suas questões, suas dúvidas seus complexos temáticos, a escola é o local para se colocar tudo em cima da mesa e discutir, para que as idéias e as informações sejam avaliadas, compartilhadas com colegas.

È preciso aprender a aprender, ou seja, é preciso que o aluno entenda os processos de se obter informações e discuti-las, validá-las ou não, a partir dos temas complexos ou de situações problemas gerados pela vivencia, o aluno precisa aprender a organizar suas idéias e a usar os conteúdos como instrumentos para entender o mundo em que vive. Para tanto, é preciso pensar em uma escola que trabalhe com a curiosidade do aluno, que parta de situações-problemas que são existenciais para os seus alunos. É necessário que a Matemática Financeira forneça um ensino contextualizado na vida do aluno e da sua comunidade, é preciso ter liberdade para apresentar idéias, para divulgá-las e estar pronto para colocá-las em prova; nesse processo, é possível esperar a formação de um cidadão que aprenda a ler o mundo em que vive e assim, aprenda a ser livre.

\section{O ENSINO DA MATEMÁTICA HOJE: PROBLEMAS E DESAFIOS}

O ensino de Matemática vem sofrendo grandes modificações nos últimos 
anos em todo o mundo, no entanto, em que pesem os estudos e pesquisas recentes de educadores matemáticos, os resultados de avaliações nacionais e internacionais revelam que a aprendizagem matemática dos alunos no ensino fundamental e médio é ainda insuficiente em muitos dos países do mundo.

Apesar dos esforços concentrados para melhorar o ensino da matemática, é possível antever muito trabalho pela frente, avaliações realizadas nas séries iniciais do ensino fundamental mostram que os aluno não têm um bom desempenho em questões que envolvem a descoberta da operação que resolve um determinado problema.

Ensinar matemática de forma isolada das demais áreas do conhecimento, explorar conhecimentos matemáticos apenas como pré-requisito para depois ensinar mais matemática, não contribui muito para a formação integral do aluno. Em virtude da maneira como muitas vezes a matemática é abordada, ela é vista por muitos alunos como uma matéria difícil, quase impossível de ser aprendida, felizmente estamos vivendo um processo de transformações, novas orientações curriculares que apresentam o ensino de matemática voltado à formação da cidadania, vêm sendo implementado no país.

Nos últimos anos, há incentivos e estudos para desenvolver no aluno competências necessárias para o exercício pleno da cidadania. Essa preocupação vem se concretizando em diferentes propostas de ensino, tais propostas destacam que é preciso explorar a matemática partindo de problemas encontrados no cotidiano e nas demais áreas do conhecimento, trabalhando com conteúdos variados, explorando de forma equilibrada e articulada e usando da melhor forma possível, recursos tecnológicos disponíveis como instrumentos de aprendizagem.

O exercício da cidadania pressupõe que as pessoas desenvolvam sua capacidade de aprender, tendo como meios o domínio da leitura, da escrita e dos conhecimentos matemáticos, de tal forma que possam compreender o mundo, o ambiente natural, cultural e político a sua volta, os valores que fundamentam a sociedade para nela atuar de forma crítica e participativa.

Neste sentido, a matemática traz grandes contribuições, pois têm relações estreitas com diversas áreas do conhecimento e da atividade humana, é um instrumento importante para as demais ciências e pode ser mais bem aprendida quando analisada sobre a perspectiva interdisciplinar, ela faz parte da vida de todos 
nós, sendo aplicada em diversas situações do dia a dia, pois é fruto da criação humana, pode ser aprendida por todas as pessoas e não apenas pelas mais talentosas, o importante é perceber que desde cedo, a matemática pode ajudar a potencializar capacidades como as de observação, projeção, abstração, entre outras, essas capacidades favorecem o desenvolvimento do raciocínio lógico e da criatividade.

O desafio que se apresenta, para uma proposta de trabalho com matemática que vise à aprendizagem significativa, é explorar uma grande variedade de idéias matemáticas, além de incorporar contextos do cotidiano de forma a desenvolver diferentes visões da realidade. Com isso, há condições de que o estudo de diferentes conteúdos seja feito de modo significativo para o aluno, não justificado apenas como pré-requisito para o estudo de outro conteúdo, esse procedimento abre perspectivas para uma abordagem interdisciplinar, ou seja, o ensino de matemática deve ser pensado numa perspectiva mais ampla. É fundamental trabalhar com situações práticas, relacionadas com problemas do cotidiano que forneçam contextos que possibilitem explorar de modo significativo, conceitos e procedimentos matemáticos.

Entretanto, deve ficar claro que o que se defende não é que o ensino de Matemática se justifique por desenvolver as capacidades de raciocínio. Existem hábitos de pensamento específicos para a Matemática e outros que se aplicam a domínios mais amplos. Desenvolvendo os dois tipos, podemos preparar os alunos para estudos avançados de Matemática e, ao mesmo tempo, atender as necessidades de alunos que podem não ter desenvolvido um especial interesse ou aptidão para a Matemática. Desenvolver esses hábitos, além de fornecer uma base sólida sobre como a Matemática é realmente feita, serve aos objetivos gerais da educação para a maior parte dos alunos. (BERTONI, 2008, pg. 178)

Uma das finalidades da matemática tendo em vista a construção da cidadania e a constituição do aluno como sujeito da aprendizagem, é seu caráter prático, ou seja, ela permite resolver problemas do cotidiano das pessoas, ajudá-las a não ser enganadas, a exercer sua cidadania; no entanto, a aprendizagem da matemática não deve reduzir-se aos problemas da vida prática, deve também contribuir para o desenvolvimento do raciocínio, da lógica, da coerência, ultrapassando assim os aspectos práticos dessa área do conhecimento; no entanto, no mundo em que vivemos repletos de informações expressas em linguagens 
diversas, uma das finalidades da matemática, é oferecer ferramentas para decodificar informações; um dos aspectos mais atuais que o ensino de matemática deve contemplar é a seleção e a organização de informações relevantes.

Num mundo com uma grande massa de informações, algumas contraditórias, outras pouco relevantes, é necessário que o cidadão consiga fazer uma triagem e uma avaliação constante, a matemática oferece inúmeras ferramentas para isso, que devem ser privilegiadas no trabalho planejado pelo professor. Os debates sociais cada vez mais envolvem informações quantitativas como base para suas reivindicações. Os indivíduos fazem julgamentos, avaliações, avaliam dados. O fracasso na utilização de noções matemáticas que permitam essas análises e julgamentos pode resultar em decisões pessoais confusas e em tomadas de decisões equivocadas tanto na vida particular como profissional.

\section{CONSIDERAÇÕES FINAIS}

O simples fato de os jovens estarem em permanente convívio social interagindo com informações e vivências diversas, os faz possuidores de conhecimentos e experiências valiosas. Essa vivência conquistada encontrará no professor o elo para chegar a novas informações, desta vez de forma sintetizada, podendo construir ou aprofundar conhecimentos.

Sendo a matemática uma ciência construída socialmente ao longo da história, é inegável o seu papel decisivo para resolver problemas da vida cotidiana e suas inúmeras aplicações no mundo do trabalho, além de sua importância para o desenvolvimento de outras áreas do conhecimento, estas constatações nos colocam diante da necessidade urgente de se pensar o ensino da disciplina em consonância com a realidade em que vivemos.

Esperamos contribuir no trabalho desenvolvido dentro de sala de aula, quando do ensino de Matemática Financeira e mostrar sua aplicabilidade, bem como sua utilização na formação de alunos, cidadãos críticos e atuantes na sociedade.

É necessário que durante a formação do aluno, haja o desenvolvimento de um número considerável de habilidades, indo muito além dos conhecimentos específicos e dos procedimentos corriqueiros, trata-se de uma matemática em que o desenvolvimento dos conteúdos seja dado numa perspectiva de 
interdisciplinaridade e contextualização, pois, nesta etapa o ensino da Matemática Financeira deve ser compreendido como uma parcela do conhecimento humano essencial para a formação de todos os jovens, sendo que esta, contribui para a construção de uma visão de mundo, para ler e interpretar a realidade e para desenvolver capacidades que deles serão exigidas ao longo de sua vida social e profissional.

\section{REFERÊNCIAS}

BARRETO, Benigno Filho; SILVA, Cláudio Xavier. Matemática aula por aula. Ministério da Educação/FTD

BERTONI, Eigenheer Nilza. Programa Gestão da Aprendizagem Escolar. 2008.

BRASIL. MEC. Secretaria de Educação Fundamental. Parâmetros Curriculares Nacionais: Matemática. Brasília: MEC/SEF, 1998. . MEC. Secretaria de Educação Fundamental. Parâmetros Curriculares Nacionais: Matemática. Brasília: MEC/SEF, 2000. . MEC. Secretaria de Educação Fundamental. Parâmetros Curriculares Nacionais: Matemática. Brasília: MEC/SEF, 2001.

CASTRUCCl, Giovanni A conquista da Matemática. Ministério da Educação/ FNDE.

DANTE, L.R. Tudo é matemática. São Paulo: Ática, 2002.

DIAS, Silvia; MACHADO, Alcântara. Educação Matemática. São Paulo: EDUC, 1999. MATTOS, Antonio Carlos M. O Modelo Matemático dos Juros. Uma Abordagem Sistêmica, Petrópolis: Vozes, 1992.

ROBERT, Jozsef. A Origem do Dinheiro São Paulo: Global, 1982.

SKOVSMOVE, Olé. Educação Matemática Crítica. Campinas: Papirus, 2001. 